OPEN ACCESS

Edited by:

Ildikó Rácz,

Universitätsklinikum Bonn, Germany

Reviewed by: Ernest Marshall Graham, Johns Hopkins University,

United States

Eva Maria Jimenez-Mateos,

Trinity College Dublin, Ireland

*Correspondence:

Xiaoxing Xiong

xiaoxingxiong@whu.edu.cn

Renzhong Liu

liurenzhong@whu.edu.cn

tThese authors have contributed equally to this work

Received: 08 January 2019 Accepted: 21 March 2019 Published: 11 April 2019

Citation:

Qin X, Cheng J, Zhong Y, Mahgoub OK, Akter F, Fan Y, Aldughaim M, Xie Q, Qin L, Gu L,

Jian Z, Xiong X and Liu R (2019) Mechanism and Treatment Related to Oxidative Stress in Neonatal Hypoxic-Ischemic Encephalopathy.

Front. Mol. Neurosci. 12:88 doi: 10.3389/fnmol.2019.00088

\section{Mechanism and Treatment Related to Oxidative Stress in Neonatal Hypoxic-Ischemic Encephalopathy}

\author{
Xingping Qin',2t, Jing Cheng't, Yi Zhong1, Omer Kamal Mahgoub', Farhana Akter ${ }^{2,3}$, \\ Yanqin Fan ${ }^{4}$, Mohammed Aldughaim², Qiurong Xie ${ }^{5}$, Lingxia Qin ${ }^{6}$, Lijuan Gü, \\ Zhihong Jian ${ }^{1}$, Xiaoxing Xiong ${ }^{1 *}$ and Renzhong Liu ${ }^{1 *}$
}

${ }^{1}$ Department of Neurosurgery, Renmin Hospital of Wuhan University, Wuhan, China, ${ }^{2}$ Department of Neurosurgery, Harvard Medical School, Boston, MA, United States, ${ }^{3}$ Department of Neuroscience, University of Cambridge, Cambridge, United Kingdom, ${ }^{4}$ Central Laboratory, Renmin Hospital of Wuhan University, Wuhan, China, ${ }^{5}$ Department of Gynecology and Obstetrics, Renmin Hospital of Wuhan University, Wuhan, China, ${ }^{6}$ Department of Neurology, Renmin Hospital of Wuhan University, Wuhan, China

Hypoxic ischemic encephalopathy (HIE) is a type of neonatal brain injury, which occurs due to lack of supply and oxygen deprivation to the brain. It is associated with a high morbidity and mortality rate. There are several therapeutic strategies that can be used to improve outcomes in patients with HIE. These include cell therapies such as marrow mesenchymal stem cells (MSCs) and umbilical cord blood stem cells (UCBCs), which are being incorporated into the new protocols for the prevention of ischemic brain damage. The focus of this review is to discuss the mechanism of oxidative stress in HIE and summarize the current available treatments for HIE. We hope that a better understanding of the relationship between oxidative stress and HIE will provide new insights on the potential therapy of this devastating condition.

Keywords: neonatal hypoxic ischemic encephalopathy, mechanisms and therapy, reactive oxygen species, oxidative stress, clinical biomarkers, antioxidant therapy, mitochondria

\section{INTRODUCTION}

Hypoxic ischemic encephalopathy (HIE) is a severe brain injury which occurs due to intrapartum asphyxia (Gluckman et al., 2005; Shankaran et al., 2005; Azzopardi et al., 2009). Neonatal HIE accounts for approximately $25 \%$ of global neonatal deaths (Liu et al., 2015b; Tagin et al., 2015). It has an annual incidence of 1.5 of every 1000 newborns (Kurinczuk et al., 2010), with a greater incidence in in developing countries (Azra Haider and Bhutta, 2006).

Neonates with HIE have greater incidence of cerebral palsy, cognitive impairment, growth restriction, and epilepsy (Cowan et al., 2003; Badawi et al., 2005; Lee et al., 2005). Magnetic resonance imaging (MRI) studies show that perinatal hypoxic-brain injury is characterized by structural damage to the gray matter (e.g., the basal ganglia, the thalamus, and the cortex) and to a less extent infarctions in white matter. Extensive structural damage is associated with worse motor outcomes and neurodevelopment delay (Rutherford et al., 2010a,b; Alderliesten et al., 2013).

Brain ischemia initiates a cascade of biochemical events as a result of a loss of adenosine triphosphate (ATP) and a failure of ATP-dependent ion transport pumps, leading to influx of sodium $\left(\mathrm{Na}^{+}\right)$and calcium $\left(\mathrm{Ca}^{2+}\right)$ into cells. There is also a pump failure exporting $\mathrm{Ca}^{2+}$ out 
of the cell resulting in release of neurotransmitters such as glutamate, which stimulates $\alpha$-amino-3-hydroxyl-5-methyl4-isoxazole-propionate (AMPA) and N-methyl-D-aspartate (NMDA) receptors (Arteaga et al., 2015; Davidson et al., 2015; Wu et al., 2015), leading to excitotoxicity of cells and generation of free radicals. These can initiate elements of the programmed cell death cascade via redox signaling damaging DNA, proteins, and lipids, and also compromising the integrity of the blood-brain barrier.

Studies from small and large animal models have shown that as pregnancy progresses, developing brains become increasingly vulnerable to HIE, due to the brain's high metabolic needs, leading to neuronal cell death (Volpe, 2001; Low, 2004; Vannucci and Hagberg, 2004; Bryce et al., 2005). Following HIE, cells initially experience impaired cerebral oxidative metabolism, swelling, and accumulation of extra-cellular excitatory amino acids, followed by a brief recovery before secondary energy failure ensues. Once reoxygenation takes place, reperfusion injury occurs leading to neuron cell death. Reperfusion injury includes irritant toxicity, deterioration of mitochondrial function, inflammation, activation of nitric oxide synthase (NOS), production of reactive oxygen species (ROS), and intracellular $\mathrm{Ca}^{2+}$ accumulation (Aridas et al., 2014; Arteaga et al., 2015; Davidson et al., 2015; Wu et al., 2015).

\section{OXIDATIVE STRESS AND NEONATAL BRAIN INJURY}

Neonatal brains are more susceptible to oxidative stress for a number of reasons: (1) neonatal brain is rich in fatty acids which make it particularly vulnerable to free radicals and lipid peroxidation insults; (2) compared to adults, the newborn's brain is rich in iron $\left(\mathrm{Fe}^{2+}\right)$, which plays a crucial role in growth and development. However, unbound iron can contribute to the development of free radicals. Free ions also catalyze the formation of ROS. When the newborn's brain is exposed to $\mathrm{Fe}^{2+}$ ions, hydrogen peroxide $\left(\mathrm{H}_{2} \mathrm{O}_{2}\right)$ can catalyze the formation of hydroxide $(\mathrm{OH})$ ion, which is more oxidative, thus resulting in a more severe brain damage (Aridas et al., 2014) (Figure 1); (3) the cellular structure of the immature brain has its own characteristics in different stages. The periventricular white matter in preterm infants is characterized by preferential death of immature oligodendrocytes (Ferriero, 2001), which are particularly sensitive to oxidative damage mediated by free radicals. In term infants, the basal ganglia and thalamus, which are abundant in glutamate receptors allowing glutamate binding, are prone to damage during a hypoxic-ischemic insult (Aridas et al., 2014); (4) protogenic cells of immature brain oligodendrocytes are highly sensitive to free radicals while mature brain is more tolerant of oxidative stress. Some experiments have found that the half maximal effective concentration required to scavenge $50 \%$ of $\mathrm{H}_{2} \mathrm{O}_{2}$ (EC50 value) in the immature brain was lower than in the mature brain (Ferriero, 2001); (5) the antioxidant function of immature brain tissue is imperfect. Various studies (Baud et al., 2004) have indicated that the catalase activity in the antioxidant enzyme system is increased by twofold during embryonic day 18 and day 1 after birth, glutathione peroxidase (GPx) activity is increased by threefold, and GSH content is also significantly increased. Oxidative stress activates xanthine oxidase, which accumulates in the endothelium of the cerebral capillaries, therefore exposing the blood-brain barrier to oxidative stress (Khan and Black, 2003). This will result in free radical peroxidation of cell membranes to induce the production of inflammatory cytokines and promote leukocyte adhesion to the microvascular endothelium, allowing these leukocytes to cause further damage to endothelial cells (Buonocore et al., 2001). In this way, under the action of ROS, the integrity of the blood vessel is damaged, leading to intracranial hemorrhage following neonatal oxidative stress. Free radicals and their derivatives damage brain cells by producing excessive $\mathrm{Fe}^{2+}$ (Khan and Black, 2003), during hypoxia-ischemia, $\mathrm{Fe}^{2+}$ is released from the iron pool to produce free radicals, and the free radicals can release more $\mathrm{Fe}^{2+} . \mathrm{Fe}^{2+}$ in the plasma leak through the damaged blood-brain barrier into the brain and are then absorbed directly by brain cells. $\mathrm{Fe}^{2+}$ released into the extracellular space after ischemia-reperfusion result in damage to the periventricular white matter. Moreover, the free radicals impair transmembrane $\mathrm{Na}^{+} / \mathrm{K}^{+}$-ATPase activity, initiate depolarization of cell membrane and releasing a large amount of glutamic acid. Glutamate exchanges with cystine when entering the cell, leading to oxidative stress and cell death (Khan and Black, 2003). Free radicals then activate a series of transcription factors and apoptotic proteins through the mitochondrial pathway causing apoptosis of cell death (Figure 1).

\section{MECHANISM OF OXIDATIVE STRESS IN HIE}

Oxidative stress leads to increased production of ROS and reactive nitrogen species (RNS). Low concentrations of ROS and RNS can be utilized as signaling molecules in normal physiological conditions (Wong and Crack, 2008). However, during hypoxic-ischemic injury, free radicals are produced rapidly. NMDA glutamate receptors stimulate synthesis of nitric oxide (NO) in the brain via activation of nitric oxide synthase (NOS). NO can react with superoxide, which is generated by the electron leak from the respiratory chain, particularly complexes I and III of the electron transport chain, to form peroxynitrite (ONOO-) and hydroxyl radicals $(\mathrm{OH}-)$. Subsequent $\mathrm{OH}$-mediated cell injury occurs via protein oxidation, lipid peroxidation, DNA damage, and mitochondrial inhibition (especially complex IV). Complex I and IV are also targets of ONOO-direct damage (Figure 2).

The NADPH oxidase (NOX) family is associated with a large variety of ischemic and ROS-mediated vascular diseases. The NOXs and their catalytic subunits (NOX) are unique in their role as sole enzymes responsible for ROS generation. The relevant enzymatic isoforms which are associated with vasculopathies are NOX1, NOX2, and NOX4. Genetic mutations which are associated with a loss of NOX1 functionality have been shown to lower the occurrence of ROS-induced retinopathy in mouse models. Excitotoxicity-mediated calcium channels also cause the 


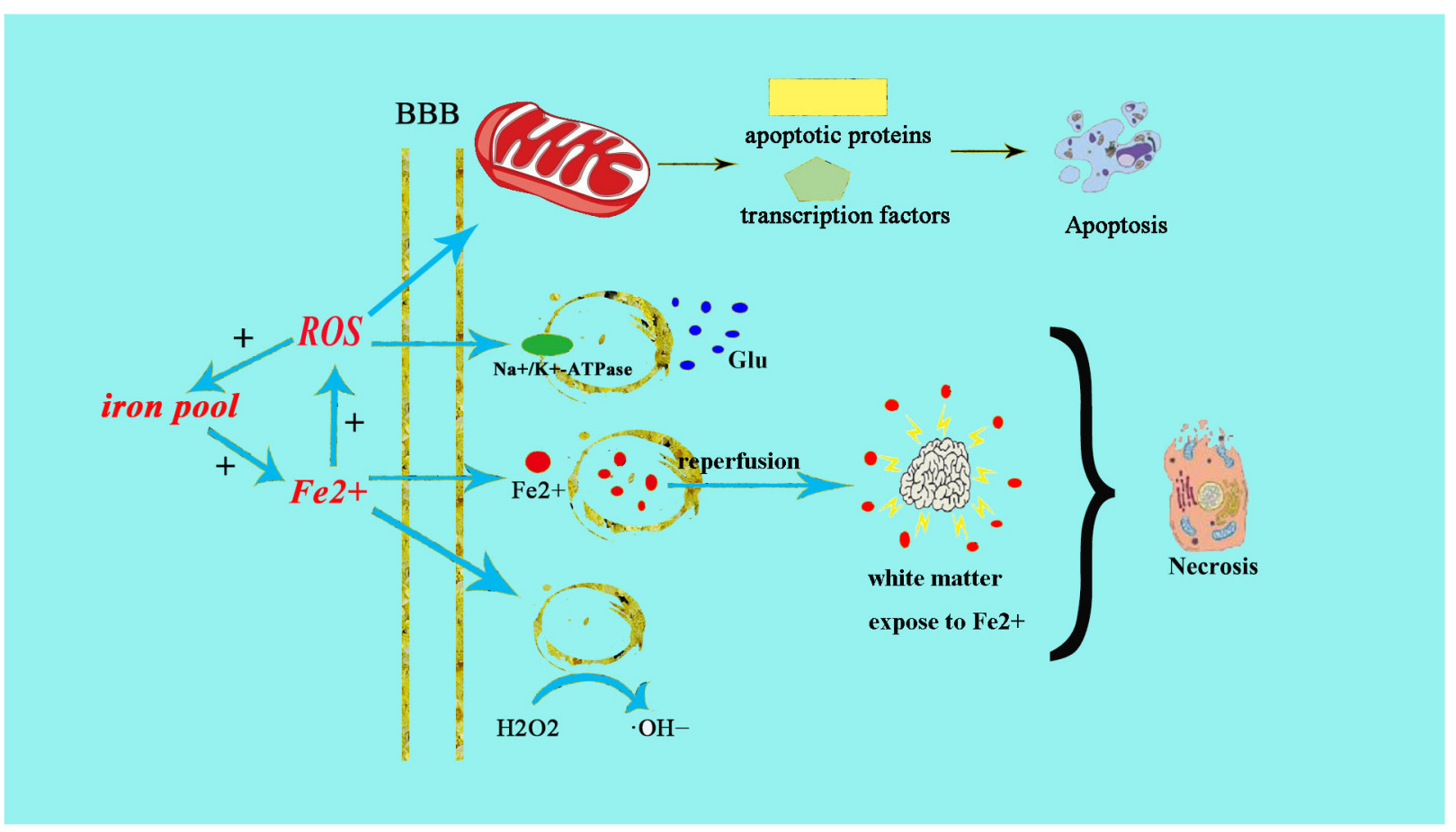

FIGURE 1 $\mathrm{Fe}^{2+}$ production after HIE result in neonatal brain cell injury. The excessive production of Fe ${ }^{2+}$ after $\mathrm{HIE}$ leads to increased production of $\mathrm{ROS}$ and $\mathrm{OH}-$. The increased production of ROS can directly cause endothelial cell damage, the same as $\cdot \mathrm{OH}_{-}$. Fe ${ }^{2+}$ can also directly damage the $\mathrm{Na}^{+} / \mathrm{K}^{+}-\mathrm{ATP}_{\mathrm{T}}$ ase and lead to the depolarization of brain cells. Then brain cells release a large amount of glutamate and produce excitotoxicity, resulting in cell damage afterward. Meanwhile, the increased glutamate can enter into cell to exchange cystine, cystine deficiency activate cell apoptosis, and cause cell death by oxidative stress.

formation of $\mathrm{O}_{2}$ via the action of NOX (Weidinger and Kozlov, 2015). $\mathrm{O}_{2}$ can be neutralized by superoxide dismutase (SOD), which transform $\mathrm{O}_{2}$ into hydrogen peroxide $\left(\mathrm{H}_{2} \mathrm{O}_{2}\right)$, and then is subsequently converted into $\mathrm{H}_{2} \mathrm{O}$ by catalase. However, the accumulation of excess $\mathrm{H}_{2} \mathrm{O}_{2}$ can lead to a further generation of $\mathrm{OH}-$ by iron-based Fenton reaction.

Oxidative stress is known to interact with the inflammatory system and create a "susceptibility window" for HIE. In the first step, it is activated by the residential immune cells such as microglia. Microglia strongly responds to hypoxic-ischemic attacks and is activated by increase in NO, glutamate, and ROS, producing a mass of inflammatory cytokines, such as IL-1 $\beta$ or TNF- $\alpha$ (Kaur et al., 2013; Knox et al., 2014). There is also activation of astrocytes, generating inflammatory cytokines, such as IL- $1 \alpha$, IL- $1 \beta$, IL- 6 , TNF- $\alpha$, and IFN- $\gamma$, which induces neuronal apoptosis, inhibits neurogenesis, and induces a direct damage of immune cells (Jellema et al., 2013). The mixture of cytokines, lymphocytes, and neutrophils exacerbate the damage of brain tissue. During the ischemia stage, neutrophils exacerbate brain damage though ROS production, decreased microvascular flow, and release of cytotoxic agents. Lymphocytes are thought to exacerbate brain injury, however, are thought to have limited role in inflammation in the neonatal brain (Tuttolomondo et al., 2008; Wang and Lu, 2008; Brait et al., 2010).

Immature brain has high oxygen consumption, contains high concentrations of $\mathrm{Fe}^{2+}$, is rich in water, and easily oxidizes unsaturated fatty acids. In addition, low-expression enzymes (SOD and GPx) of low myelination and antioxidants lead to an underdeveloped antioxidant system, making them particularly vulnerable to any oxidative damage, both ROS and RNS strongly influence excitotoxicity, which lead to cell death and mitochondrial damage (Ferriero, 2001; Perrone et al., 2010; Ikonomidou and Kaindl, 2011; Mirabelli-Badenier et al., 2011; Becker, 2012; Ten and Starkov, 2012).

Nitric oxide synthase and mitochondrial electron leakage are considered to be major contributors to ROS/RNS in immature brains (Mayurasakorn et al., 2016; Zhao et al., 2016). Expression of hydroxyl free radicals and $\mathrm{Fe}^{2+}$ increases ischemic areas in neonatal rats following $\mathrm{HIE}$ and this is partially mediated by nitric oxide (Palmer et al., 1999; Blomgren and Hagberg, 2006). Endothelial NOS and nNOS increased significantly only within hours after HIE (van den Tweel et al., 2005; Lu et al., 2015).

Mitochondria, as the primary site of oxidative metabolism, produce ATP as the "home of energy" (Ergenekon and Gucuyener, 1998; Ablikim et al., 2014). During the process of HIE, oxidative stress plays an important role in mitochondrial changes, which including mitochondrial dysfunction, ischemic starvation, reperfusion-induced hyperactivation, and delayed neuronal death. Mitochondria play a great role in the production of ROS, they are also susceptible to oxidative stress leading to cell death (Figure 1) (Acin-Perez et al., 2010; Sanderson et al., 2013). Cytochrome $\mathrm{C}$ is a crucial step in the induction of apoptosis when it released from the mitochondria. In order for this to happen, it must be separated from the cardiolipin (which is rich in 


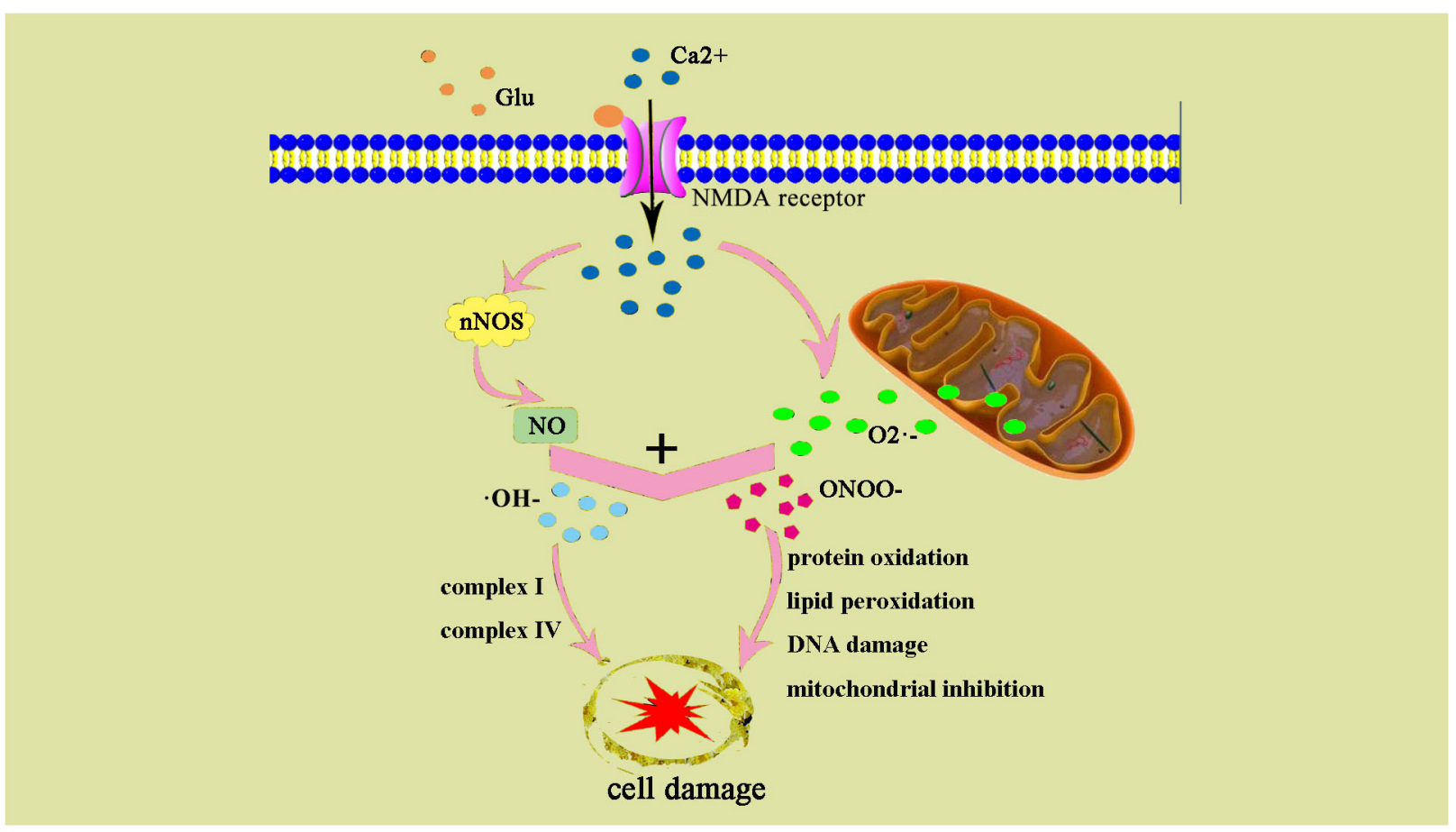

FIGURE 2 | ONOO- and damage cell schematic after the occurrence of HIE generation. After the occurrence of HIE, a large amount of Ca ${ }^{2+}$ internal flow leads to NOS generates $\mathrm{NO}, \mathrm{NO}$, and superoxide $\mathrm{O} 2-$ generate $\mathrm{ONOO}-$, an excessive amount of ONOO- can also result in an increase of .OH-. ONOO- and . $\mathrm{OH}-\mathrm{lead}$ to protein changes and degeneration, they also contribute to lipid peroxidation and DNA damage.

polyunsaturated fatty acids) inside the mitochondria. Numerous studies have suggested that an increased ROS production may promote the release of cytochrome $\mathrm{C}$ from the mitochondrial inner membrane as a catalyst for cardiolipin oxidation (Petrosillo et al., 2001, 2003; Turrens, 2003). Due to the increase of ROS during HIE, the tightly bounded or loosely coupled CytC were disrupted released in the mitochondrial membrane; Fourth, the pro-apoptotic proteins which including Bid, Bad, Bax, Bak, Bok, and Bim will be increased in numbers outside the mitochondrial membrane, then have bound to Apaf-1 forming the complex of Apaf-1/caspase-9/Sitka, which lastly inactivated caspase-3, leading to neuronal apoptosis and death (Kagan et al., 2005; Nakka et al., 2008).

\section{OXIDATIVE STRESS AND CLINICAL BIOMARKERS OF HIE}

Providing tools that quickly and accurately diagnose oxidative stress and response can undoubtedly help improve the diagnosis and prognosis of newborns. It is often difficult to perform frequent venipuncture in newborn and therefore non-invasive diagnostic tools, which are cost effective and easy to use are sought (Hardwick et al., 2012). Recent changes in oxidative status over time following specific therapeutic interventions can be monitored non-invasively with repeated urinalysis (Biomarkers Definitions Working and Group, 2001; Kuligowski et al., 2014). Although highly reliable methods have been proposed to support multiple analytical assays, the use of different biological fluids in neonatology as oxidative stress biomarkers is limited due to the requirement for complex equipment, highly specialized technicians, and cost (Saugstad et al., 2008; Vento et al., 2009; Perlman et al., 2010; Kuligowski et al., 2015). The quantification of oxidative stress is based upon measurements of biomarkers, biological fluids, and tissues that reflect the risk of oxidative stress on lipids, proteins, and DNA or increase damage to macromolecules. Biomarkers for oxidative stress include prostaglandins and non-protein bound iron (NPBI) biomarkers, both of which can be considered as indicators of the prognosis of the disease (Buonocore et al., 2003; Milne et al., 2011; Kapadia et al., 2013). Oxidative stress can be quantified by measuring the levels of prostaglandin $\mathrm{F}$ (2alpha)like compounds, which are derived from the free radical mediated, non-ezymatic oxidation of arachidonic acid (Tonni et al., 2014). The intermediates formed during this reaction undergo 5-exo-trig cyclization and secondary addition of oxygen molecules, forming a prostaglandin-like compound, which are then reduced to F2-isoprostanes (F2-isoPs) (Jahn et al., 2008; Leung et al., 2015). These products are more stable and can thus be more easily detected in biological fluids (Galano et al., 2013). F2-IsoPs can be detected using gas chromatography and mass spectrometry. Other prostanes, which can also be used as reliable markers of oxidative damage, include F3-isoPs derived from peroxidation of eicosapentaenoic acid (EPA) (Kapadia et al., 2013). Currently, there is scant literature providing evidence of the relationship between oxidative stress indicators 
and the degree of brain damage and therefore needs to be explored further.

\section{TREATMENT OF NEONATAL OXIDATIVE STRESS BRAIN INJURY}

There are numerous therapeutic strategies for neonatal oxidative stress. These include mitochondrial therapy, free radical production inhibition, excitatory amino acid antagonists, nitric oxide inhibition, stem cell therapy, therapeutic hypothermia, and hyperbaric oxygen therapy.

\section{Mitochondrial Therapy}

Much attention has been paid to the mitochondrial protein targets to keep a normal mitochondrial function. Although numerous therapies have been approved for clinical trials, current treatment strategies remain imperfect. There has been an increased interest in the use of small molecule inhibitors and activators that are targeted to mitochondrion (Leaw et al., 2017) tetra- and triphenylphosphonium (TPP), as well as multi-modal delivery of mitochondria-penetrating peptides (Smith et al., 2011; Silachev et al., 2015). Targeting bioactive therapeutics and antioxidants as an alternative to mitochondrion is gradually becoming a feasible method for the development of adjunct therapies.

Coenzyme Q10 (CoQ10) (a direct regulator of mitochondrial function) can reduce the product of ROS through the mitochondrial complex. CoQ10 have been found to be a neuroprotective agent in various animal models such as rodent models of Alzheimer's disease (Li et al., 2007), middle cerebral artery occlusion (MCAO) (Belousova M. et al., 2016; Belousova M.A. et al., 2016) with or without hyperglycemia (Lu et al., 2017), and in traumatic brain injuries (Kalayci et al., 2011), However its' role in neonatal hypoxic ischemic brain injury is yet to be explored.

Metformin have been proven to restrict mitochondrial respiration through a direct suppression of mitochondrial complex I in the respiratory chain (Owen et al., 2000; Andrzejewski et al., 2014). Metformin can act on inflammatory $\mathrm{T}$ cells by inhibiting the use of 2-deoxyglucose in glycolysis in rodent models of lupus, as well as inhibiting the production of interleukin $1 \beta$ (IL1 $\beta$ ) in LPS-induced sepsis (Carey et al., 2015). In the rat model of metabolic syndrome, maternal metformin treatment does well in preventing fetal inflammation, which is a risk factor for perinatal HIE (Desai et al., 2013). By applying an HIE rat model, metformin administration in neonatal brain is beneficial for the oligodendrocyte survival with consequent amelioration of HIE-induced myelination and behavior deficits (Owen et al., 2000).

Mitoquinone (MitoQ) is a potent and an effective antioxidant used to treat structural mitochondrial 1 damage, leading to an inhibition of lipid peroxidation and reduction of superoxide production as well as further ROS generation (Maguire et al., 1989; Ernster et al., 1992; Kelso et al., 2001; Reddy, 2006). MitoQ is a known ubiquinone derivative conjugated to TPP cation. In rat models of ischemia-reperfusion injury, MitoQ has shown a protective effect (Adlam et al., 2005). MitoQ had reduced the increased left ventricular pressure in perfused rat hearts that were subjected to ischemic injury and had a beneficial effects on respiratory control ratio, complex I, and aconitase activity (Adlam et al., 2005; Milagros Rocha and Victor, 2007). MitoQ may be a suitable treatment option in cerebrovascular diseases (CVDs) by reducing mitochondrial oxidative injury. The role of MitoQ in hypoxic-ischemic injury in the brain is not fully known (Ham and Raju, 2017); however, it may have a neuroprotective role in the thalamus (Hobbs et al., 2008).

\section{Free Radical Production Inhibitors and Free Radical Scavengers}

Allopurinol is a specific inhibitor of xanthine oxidase, which can competitively inhibit xanthine oxidase and reduce the produce of oxygen free radicals in reperfusion. Allopurinol consumed by pregnant mothers leads to reduction in the level of S100B protein (a marker of brain injury in cord blood) in the infant (Casetta et al., 2012). It has been shown that allopurinol serves as a chelator for NPBI and direct scavenger for free radicals, and thus may play a role in HIE treatment (Torrance et al., 2009; Kaandorp et al., 2010; Buonocore et al., 2012; Chaudhari and McGuire, 2012).

Deferoxamine is an iron chelator, which binds free iron and enhances its elimination. Deferoxamine crosses the blood-brain barrier and chelates non-bound protein iron (NBPI). In animal models of hypoxia-ischemia, it can reduce severity of brain injury and improve cerebral metabolism (Palmer, 1995).

Erythropoietin (EPO) is required for normal brain development. EPO increases the expression of anti-apoptotic genes, inhibits inflammation, reduces oxygen free radicals, decreases caspases protease activation, upregulates the PI3K/AKT, STAT5, and ERK signaling pathways (Peeters-Scholte et al., 2003; Park et al., 2006; Robertson et al., 2012).

Melatonin is a potent endogenous indoleamine, which has anti-oxidant, anti-inflammatory, and anti-apoptotic effects in HIE. Melatonin can freely cross blood-brain barrier and is thus attractive as a therapeutic agent for HIE (Lee et al., 2006; Carloni et al., 2008; Alonso-Alconada et al., 2013).

$\mathrm{N}$-acetylserotonin (NAC)is a precursor of glutathione synthesis and an effective sulfhydryl-containing antioxidant. It is a scavenger of oxygen free radicals, increases glutathione levels, reduces redox potential, decreases cell death, reduces inflammatory cytokines, and inhibits NOS (Khan et al., 2004; Huang et al., 2008; Robertson et al., 2013). NAC attenuates hypoxi-ischemic brain injury in neonatal rats (Sekhon et al., 2003) and can be combined with systemic hypothermia to reduce brain injury (Park et al., 2015; Nie et al., 2016). NAC can attenuate demyelination in the corpus callosum, a white matter region which is particularly vulnerable to HIE (Jatana et al., 2006). Daily NAC $(50 \mathrm{mg} / \mathrm{kg})$ administration in rats in combination with hypothermia has been shown to increase myelin expression (Nie et al., 2016), improved brain function (Nie et al., 2016), and long-term neuromotor outcome (Park et al., 2015).

Superoxide dismutase is a radical scavenging enzyme, which may be useful in reducing brain injury; however, its 
applications are limited to poor permeability across the BBB. SOD encapsulated with biodegradable poly (D, L-lactide coglycolide) nanoparticles (SOD-NPs) has been shown to effectively reduce brain infarct volume, edema, ROS formation, and neuroprotection in a rat model of cerebral ischemia-reperfusion injury (Reddy and Labhasetwar, 2009).

\section{The Role of Nitric Oxide}

Nitric oxide may be either neuroprotective or neurotoxic during hypoxia-ischemia brain injury. Excessive NO production can lead to excitotoxicity, apoptosis, and inflammation. NO produced from endothelial NOS can play a neuroprotective role by preventing neuronal injury and maintaining cerebral blood flow. However, increased endothelial nitric oxide production can also promote endothelial dysfunction (Liu and Mu, 2014; Liu et al., 2015a,c).

\section{Magnesium Therapy}

Magnesium is an attractive therapeutic agent for HIE due to its numerous neuroprotective effects. Magnesium is a NMDA receptor antagonist and prevents excitotoxicity by reducing calcium or glutamate. Magnesium also reduces inflammation and oxidative stress (McCord, 1985).

\section{Stem Cell Therapy}

Recent studies suggest bone marrow derived mesenchymal stem cells (BM-MSCs) and umbilical cord blood derived mesenchymal stem cells (UCB-MSCs) may play a role in HIE. Cell therapies, in particular, the cord blood stem is thought to provide protection from inflammation, apoptosis, oxidative stress, enhance regeneration, immune regulation, and antiinflammatory effect (Figure 3). It is well known that components of the umbilical cord blood have the most effective damagemediated inflammation for the treatment of the brain. Specific populations of cells, such as endothelial progenitor cells (EPCs) and MSCs, which been found in umbilical cord blood and tissue, have been proved to have potential utility in reducing the inflammatory processes that result from brain damage. MSCs have a strong immunomodulatory effect that protects against neuroinflammatory cascades that are triggered by HIE (Wasielewski et al., 2012; Li et al., 2016; Paton et al., 2017). Umbilical cord blood stem cell (UCBC) administration can also reduce the insult of white matter damage through a combination of anti-inflammatory or any other treatment options in HIE (Nakka et al., 2008). It is expected that further preclinical studies will optimize treatment options and require clinical trials to demonstrate the efficacy and safety for patients.

\section{Hyperbaric Oxygen Therapy}

Hyperbaric oxygen therapy refers to a method of treating the body to inhale pure oxygen or high concentrations of oxygen at a level higher than one standard atmosphere. The study found that hyperbaric oxygen therapy may be through the induction of brain tissue SOD expression, thereby enhancing the organs' antioxidant stress injury. However, the current application parameters of these therapeutic measures have not yet been unified, the timing of the application is still uncertain, and the exact effect still needs to be studied with multiple centers (Liu et al., 2013).

\section{Therapeutic Hypothermia}

Therapeutic hypothermia can be classified according to the temperature as mild $\left(32-35^{\circ} \mathrm{C}\right)$, moderate $\left(28-32^{\circ} \mathrm{C}\right)$, and deep $\left(<28^{\circ} \mathrm{C}\right)$. Induced moderate hypothermia is currently used as the mainstay therapeutic tool for HIE, validated by both clinical trials and experimental evidence. However, the long-term success of this treatment with regards to outcomes is inconclusive. Reduction in brain temperature enhances maintenance of high energy ATP stores during hypoxia-ischemia. It also normalizes

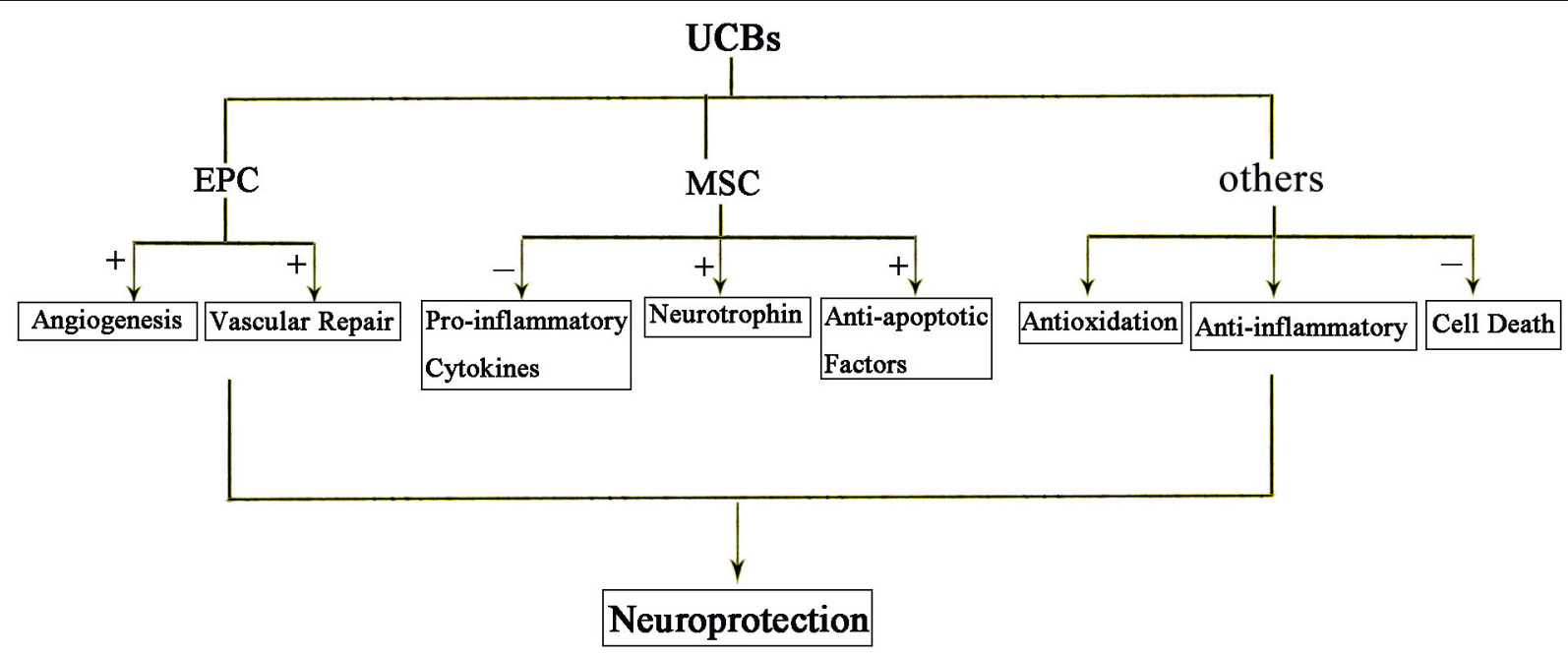

FIGURE 3 | The protective effects of UCBs following HIE. Injection of cord blood stem cells has neuroprotective effects. Among them, EPC mainly promotes angiogenesis and repair. MSC acts through anti-inflammatory, secreted neurotrophic factors and anti-apoptotic factors. In short, anti-inflammatory and anti-oxidation and prevention of cell death are the three main mechanisms of action of cord blood stem cells. 
protein synthesis and modulates activation of microglia and cytokines (Gulczynska and Gadzinowski, 2012). Therapeutic hypothermia leads to a decrease in cerebral metabolism by $5 \%$ for every degree Celsius reduction in temperature (Bain et al., 2014). Experimental studies in animals have shown that hypothermia can lead to reduction in neuronal cell death by reducing release of excitatory amino acids such as glutamate and reducing production of nitric oxide and free radicals (Wassink et al., 2014).

Several randomized controlled trials show that moderate therapeutic hypothermia is beneficial for attenuating neurodevelopment delay and mortality rates when initiated at less than $6 \mathrm{~h}$ for infants at 36 weeks' or later gestation. Therapeutic hypothermia is usually continued for $72 \mathrm{~h}$, followed by gradual rewarming over $12 \mathrm{~h}$ (Gluckman et al., 2005; Azzopardi et al., 2009). Hypothermia initiated after $6 \mathrm{~h}$ may have benefit but there remains uncertainty regarding its effectiveness (Laptook et al., 2017). Inclusion criteria for patients suitable for treatment include newborns aged $>35$ weeks with evidence of asphyxia such as $\mathrm{pH}<7.0$ of cord blood, Apgar score of less than 5 in the first $10 \mathrm{~min}$ of life or requirement for mechanical ventilation after the first $10 \mathrm{~min}$ of life, and evidence of encephalopathy (Silveira and Procianoy, 2015).

The two most common methods of inducing hypothermia include whole body cooling using a cooling blanket and selective head cooling with mild systemic hypothermia. Several groups have conducted comparison studies to determine which method is preferable for HIE treatment. There appears to be a higher incidence of hypoxic-ischemic lesions on MRI from patients who received selective head cooling vs whole body cooling (Sarkar et al., 2012). However, there appear to be no significant differences when comparing multi-organ dysfunction in infants receiving either method of treatment. Whole body cooling appears to be more favorable at present although selective head cooling may be just as useful in infants

\section{REFERENCES}

Ablikim, M., Achasov, M. N., Ai, X. C., Albayrak, O., Albrecht, M., Ambrose, D. J., et al. (2014). Observation of eta'->pi+ pi pi+ pi- and eta'$>$ pi+pi- pi0 pi0. Phys. Rev. Lett. 112:251801. doi: 10.1103/PhysRevLett. 112.251801

Acin-Perez, R., Hoyos, B., Gong, J., Vinogradov, V., Fischman, D. A., Leitges, M., et al. (2010). Regulation of intermediary metabolism by the PKCdelta signalosome in mitochondria. FASEB J. 24, 5033-5042. doi: 10.1096/fj.10166934

Adlam, V. J., Harrison, J. C., Porteous, C. M., James, A. M., Smith, R. A., Murphy, M. P., et al. (2005). Targeting an antioxidant to mitochondria decreases cardiac ischemia-reperfusion injury. FASEB J. 19, 1088-1095. doi: 10.1096/fj. 05-3718com

Alderliesten, T., Nikkels, P. G., Benders, M. J., De Vries, L. S., and Groenendaal, F. (2013). Antemortem cranial MRI compared with postmortem histopathologic examination of the brain in term infants with neonatal encephalopathy following perinatal asphyxia. Arch. Dis. Child Fetal Neonatal. Ed. 98, F304F309. doi: 10.1136/archdischild-2012-301768

Alonso-Alconada, D., Alvarez, A., Arteaga, O., Martinez-Ibarguen, A., and Hilario, E. (2013). Neuroprotective effect of melatonin: a novel therapy against perinatal hypoxia-ischemia. Int. J. Mol. Sci. 14, 9379-9395. doi: 10.3390/ ijms 14059379 with less severe EEG changes (Sarkar et al., 2009). However, further large randomized controlled trials must be conducted to identify the best method for reducing both mortality and neurodevelopmental delay in HIE.

\section{CONCLUSION}

In short, the pathogenesis of neonatal brain injury is extremely complex, there is a growing concern about oxidative stress in neonatal brain damage due to the neonatal brain own characteristics being more susceptible to oxidative stress injury. As a result, there is not an exact and effective treatment for neonatal brain injury. This article focuses on the mechanism of oxidative stress in neonatal brain injury. It is hoped that it would help to improve the public's understanding of neonatal brain injury and help to diagnose neonatal brain injury indicators, prevention, and treatment measures.

\section{AUTHOR CONTRIBUTIONS}

All authors listed have made a substantial, direct and intellectual contribution to the work, and approved it for publication.

\section{FUNDING}

This study was supported by the National Natural Science Foundation of China (81870939 and 81571147 to XX).

\section{ACKNOWLEDGMENTS}

We thank Xueting Wu for her artistic drawing.

Andrzejewski, S., Gravel, S. P., Pollak, M., and St-Pierre, J. (2014). Metformin directly acts on mitochondria to alter cellular bioenergetics. Cancer Metab. 2:12. doi: 10.1186/2049-3002-2-12

Aridas, J. D., Yawno, T., Sutherland, A. E., Nitsos, I., Ditchfield, M., Wong, F. Y., et al. (2014). Detecting brain injury in neonatal hypoxic ischemic encephalopathy: closing the gap between experimental and clinical research. Exp. Neurol. 261, 281-290. doi: 10.1016/j.expneurol.2014.07.009

Arteaga, O., Revuelta, M., Uriguen, L., Alvarez, A., Montalvo, H., and Hilario, E. (2015). Pretreatment with resveratrol prevents neuronal injury and cognitive deficits induced by perinatal hypoxia-ischemia in rats. PLoS One 10:e0142424. doi: 10.1371/journal.pone.0142424

Azra Haider, B., and Bhutta, Z. A. (2006). Birth asphyxia in developing countries: current status and public health implications. Curr. Probl. Pediatr. Adolesc. Health Care 36, 178-188. doi: 10.1016/j.cppeds.2005.11.002

Azzopardi, D. V., Strohm, B., Edwards, A. D., Dyet, L., Halliday, H. L., Juszczak, E., et al. (2009). Moderate hypothermia to treat perinatal asphyxial encephalopathy. N. Engl. J. Med. 361, 1349-1358. doi: 10.1056/NEJMoa0900854

Badawi, N., Felix, J. F., Kurinczuk, J. J., Dixon, G., Watson, L., Keogh, J. M., et al. (2005). Cerebral palsy following term newborn encephalopathy: a population-based study. Dev. Med. Child Neurol. 47, 293-298. doi: 10.1017/ S0012162205000575

Bain, A. R., Morrison, S. A., and Ainslie, P. N. (2014). Cerebral oxygenation and hyperthermia. Front. Physiol. 5:92. doi: 10.3389/fphys.2014.00092 
Baud, O., Greene, A. E., Li, J., Wang, H., Volpe, J. J., and Rosenberg, P. A. (2004). Glutathione peroxidase-catalase cooperativity is required for resistance to hydrogen peroxide by mature rat oligodendrocytes. J. Neurosci. 24, 1531-1540. doi: 10.1523/JNEUROSCI.3989-03.2004

Becker, K. J. (2012). Activation of immune responses to brain antigens after stroke. J. Neurochem. 123(Suppl. 2), 148-155. doi: 10.1111/j.1471-4159.2012.07953.x

Belousova, M., Tokareva, O. G., Gorodetskaya, E., Kalenikova, E. I., and Medvedev, O. S. (2016). Intravenous treatment with coenzyme Q10 improves neurological outcome and reduces infarct volume after transient focal brain ischemia in rats. J. Cardiovasc. Pharmacol. 67, 103-109. doi: 10.1097/FJC.0000000000000320

Belousova, M. A., Tokareva, O. G., Gorodetskaya, E. A., Kalenikova, E. I., and Medvedev, O. S. (2016). Neuroprotective effectiveness of intravenous ubiquinone in rat model of irreversible cerebral ischemia. Bull. Exp. Biol. Med. 161, 245-247. doi: 10.1007/s10517-016-3387-1

Biomarkers Definitions Working and Group (2001). Biomarkers and surrogate endpoints: preferred definitions and conceptual framework. Clin. Pharmacol. Ther. 69, 89-95. doi: 10.1067/mcp.2001.113989

Blomgren, K., and Hagberg, H. (2006). Free radicals, mitochondria, and hypoxiaischemia in the developing brain. Free Radic. Biol. Med. 40, 388-397. doi: 10.1016/j.freeradbiomed.2005.08.040

Brait, V. H., Jackman, K. A., Walduck, A. K., Selemidis, S., Diep, H., Mast, A. E., et al. (2010). Mechanisms contributing to cerebral infarct size after stroke: gender, reperfusion, T lymphocytes, and Nox2-derived superoxide. J. Cereb. Blood Flow Metab. 30, 1306-1317. doi: 10.1038/jcbfm.2010.14

Bryce, J., Boschi-Pinto, C., Shibuya, K., Black, R. E., Who Child, Health Epidemiology, et al. (2005). WHO estimates of the causes of death in children. Lancet 365, 1147-1152. doi: 10.1016/S0140-6736(05)71877-8

Buonocore, G., Perrone, S., and Bracci, R. (2001). Free radicals and brain damage in the newborn. Biol. Neonate 79, 180-186. doi: 10.1159/000047088

Buonocore, G., Perrone, S., Longini, M., Paffetti, P., Vezzosi, P., Gatti, M. G., et al. (2003). Non protein bound iron as early predictive marker of neonatal brain damage. Brain 126, 1224-1230. doi: 10.1093/brain/awg116

Buonocore, G., Perrone, S., Turrisi, G., Kramer, B. W., and Balduini, W. (2012). New pharmacological approaches in infants with hypoxicischemic encephalopathy. Curr. Pharm. Des. 18, 3086-3100. doi: 10.2174/1381612811209023086

Carey, B. W., Finley, L. W., Cross, J. R., Allis, C. D., and Thompson, C. B. (2015). Intracellular alpha-ketoglutarate maintains the pluripotency of embryonic stem cells. Nature 518, 413-416. doi: 10.1038/nature13981

Carloni, S., Perrone, S., Buonocore, G., Longini, M., Proietti, F., and Balduini, W. (2008). Melatonin protects from the long-term consequences of a neonatal hypoxic-ischemic brain injury in rats. J. Pineal Res. 44, 157-164. doi: 10.1111/j. 1600-079X.2007.00503.x

Casetta, B., Longini, M., Proietti, F., Perrone, S., and Buonocore, G. (2012). Development of a fast and simple LC-MS/MS method for measuring the F2isoprostanes in newborns. J. Mater. Fetal Neonatal Med. 25(Suppl. 1), 114-118. doi: $10.3109 / 14767058.2012 .664856$

Chaudhari, T., and McGuire, W. (2012). Allopurinol for preventing mortality and morbidity in newborn infants with hypoxic-ischaemic encephalopathy. Cochrane Datab. Syst. Rev. CD006817. doi: 10.1002/14651858.CD006817.pub3

Cowan, F., Rutherford, M., Groenendaal, F., Eken, P., Mercuri, E., Bydder, G. M., et al. (2003). Origin and timing of brain lesions in term infants with neonatal encephalopathy. Lancet 361, 736-742. doi: 10.1016/S0140-6736(03)12 658-X

Davidson, J. O., Wassink, G., Van Den Heuij, L. G., Bennet, L., and Gunn, A. J. (2015). Therapeutic hypothermia for neonatal hypoxic-ischemic encephalopathy - Where to from Here? Front. Neurol. 6:198. doi: 10.3389/ fneur.2015.00198

Desai, N., Roman, A., Rochelson, B., Gupta, M., Xue, X., Chatterjee, P. K., et al. (2013). Maternal metformin treatment decreases fetal inflammation in a rat model of obesity and metabolic syndrome. Am. J. Obstet. Gynecol. 209, e131-e139. doi: 10.1016/j.ajog.2013.05.001

Ergenekon, E., and Gucuyener, K. (1998). Nitric oxide in developing brain. Eur. J. Paediatr. Neurol. 2, 297-301. doi: 10.1016/S1090-3798(98)80004-4

Ernster, L., Forsmark, P., and Nordenbrand, K. (1992). The mode of action of lipid-soluble antioxidants in biological membranes: relationship between the effects of ubiquinol and vitamin $\mathrm{E}$ as inhibitors of lipid peroxidation in submitochondrial particles. Biofactors 3, 241-248.
Ferriero, D. M. (2001). Oxidant mechanisms in neonatal hypoxia-ischemia. Dev. Neurosci. 23, 198-202. doi: 10.1159/000046143

Galano, J. M., Mas, E., Barden, A., Mori, T. A., Signorini, C., De Felice, C., et al. (2013). Isoprostanes and neuroprostanes: total synthesis, biological activity and biomarkers of oxidative stress in humans. Prostaglandins Other Lipid Mediat. 107, 95-102. doi: 10.1016/j.prostaglandins.2013.04.003

Gluckman, P. D., Wyatt, J. S., Azzopardi, D., Ballard, R., Edwards, A. D., Ferriero, D. M., et al. (2005). Selective head cooling with mild systemic hypothermia after neonatal encephalopathy: multicentre randomised trial. Lancet 365, 663-670. doi: 10.1016/S0140-6736(05)17946-X

Gulczynska, E., and Gadzinowski, J. (2012). [Therapeutic hypothermia for neonatal hypoxic-ischemic encephalopathy]. Ginekol. Pol. 83, 214-218.

Ham, P. B. III, and Raju, R. (2017). Mitochondrial function in hypoxic ischemic injury and influence of aging. Prog Neurobiol. 157, 92-116. doi: 10.1016/j. pneurobio.2016.06.006

Hardwick, J. M., Chen, Y. B., and Jonas, E. A. (2012). Multipolar functions of BCL-2 proteins link energetics to apoptosis. Trends Cell Biol. 22, 318-328. doi: 10.1016/j.tcb.2012.03.005

Hobbs, C. E., Murphy, M. P., Smith, R. A., and Oorschot, D. E. (2008). Neonatal rat hypoxia-ischemia: effect of the anti-oxidant mitoquinol, and S-PBN. Pediatr. Int. 50, 481-488. doi: 10.1111/j.1442-200X.2008.02705.x

Huang, H. M., Yu, J. Y., Ou, H. C., and Jeng, K. C. (2008). Effect of naloxone on the induction of immediately early genes following oxygen- and glucosedeprivation in PC12 cells. Neurosci. Lett. 438, 252-256. doi: 10.1016/j.neulet. 2008.04.036

Ikonomidou, C., and Kaindl, A. M. (2011). Neuronal death and oxidative stress in the developing brain. Antioxid. Redox Signal. 14, 1535-1550. doi: 10.1089/ars. 2010.3581

Jahn, U., Galano, J. M., and Durand, T. (2008). Beyond prostaglandins-chemistry and biology of cyclic oxygenated metabolites formed by free-radical pathways from polyunsaturated fatty acids. Angew. Chem. Int. Ed. Engl. 47, 5894-5955. doi: 10.1002/anie.200705122

Jatana, M., Singh, I., Singh, A. K., and Jenkins, D. (2006). Combination of systemic hypothermia and $\mathrm{N}$-acetylcysteine attenuates hypoxic-ischemic brain injury in neonatal rats. Pediatr. Res. 59, 684-689. doi: 10.1203/01.pdr.0000215045. 91122.44

Jellema, R. K., Lima Passos, V., Ophelders, D. R., Wolfs, T. G., Zwanenburg, A., De Munter, S., et al. (2013). Systemic G-CSF attenuates cerebral inflammation and hypomyelination but does not reduce seizure burden in preterm sheep exposed to global hypoxia-ischemia. Exp. Neurol. 250, 293-303. doi: 10.1016/ j.expneurol.2013.09.026

Kaandorp, J. J., Benders, M. J., Rademaker, C. M., Torrance, H. L., Oudijk, M. A., De Haan, T. R., et al. (2010). Antenatal allopurinol for reduction of birth asphyxia induced brain damage (ALLO-Trial); a randomized double blind placebo controlled multicenter study. BMC Pregnancy Childbirth 10:8. doi: 10.1186/1471-2393-10-8

Kagan, V. E., Tyurin, V. A., Jiang, J., Tyurina, Y. Y., Ritov, V. B., Amoscato, A. A., et al. (2005). Cytochrome $\mathrm{c}$ acts as a cardiolipin oxygenase required for release of proapoptotic factors. Nat. Chem. Biol. 1, 223-232. doi: 10.1038/nchembio727

Kalayci, M., Unal, M. M., Gul, S., Acikgoz, S., Kandemir, N., Hanci, V., et al. (2011). Effect of coenzyme Q10 on ischemia and neuronal damage in an experimental traumatic brain-injury model in rats. BMC Neurosci. 12:75. doi: 10.1186/14712202-12-75

Kapadia, V. S., Chalak, L. F., Sparks, J. E., Allen, J. R., Savani, R. C., and Wyckoff, M. H. (2013). Resuscitation of preterm neonates with limited versus high oxygen strategy. Pediatrics 132, e1488-e1496. doi: 10.1542/peds.2013-0978

Kaur, C., Rathnasamy, G., and Ling, E. A. (2013). Roles of activated microglia in hypoxia induced neuroinflammation in the developing brain and the retina. J. Neuroimm. Pharmacol. 8, 66-78. doi: 10.1007/s11481-012-9347-2

Kelso, G. F., Porteous, C. M., Coulter, C. V., Hughes, G., Porteous, W. K., Ledgerwood, E. C., et al. (2001). Selective targeting of a redox-active ubiquinone to mitochondria within cells: antioxidant and antiapoptotic properties. J. Biol. Chem. 276, 4588-4596. doi: 10.1074/jbc.M009093200

Khan, J. Y., and Black, S. M. (2003). Developmental changes in murine brain antioxidant enzymes. Pediatr. Res. 54, 77-82. doi: 10.1203/01.PDR.0000065736. 69214.20

Khan, M., Sekhon, B., Jatana, M., Giri, S., Gilg, A. G., Sekhon, C., et al. (2004). Administration of $\mathrm{N}$-acetylcysteine after focal cerebral ischemia protects brain 
and reduces inflammation in a rat model of experimental stroke. J. Neurosci. Res. 76, 519-527. doi: 10.1002/jnr.20087

Knox, R., Brennan-Minnella, A. M., Lu, F., Yang, D., Nakazawa, T., Yamamoto, T., et al. (2014). NR2B phosphorylation at tyrosine 1472 contributes to brain injury in a rodent model of neonatal hypoxia-ischemia. Stroke 45, 3040-3047. doi: 10.1161/STROKEAHA.114.006170

Kuligowski, J., Aguar, M., Rook, D., Lliso, I., Torres-Cuevas, I., Escobar, J., et al. (2015). Urinary lipid peroxidation byproducts: are they relevant for predicting neonatal morbidity in preterm infants? Antioxid Redox Signal. 23, 178-184. doi: 10.1089/ars.2015.6262

Kuligowski, J., Escobar, J., Quintas, G., Lliso, I., Torres-Cuevas, I., Nunez, A., et al. (2014). Analysis of lipid peroxidation biomarkers in extremely low gestational age neonate urines by UPLC-MS/MS. Anal. Bioanal. Chem. 406, 4345-4356. doi: 10.1007/s00216-014-7824-6

Kurinczuk, J. J., White-Koning, M., and Badawi, N. (2010). Epidemiology of neonatal encephalopathy and hypoxic-ischaemic encephalopathy. Early Hum. Dev. 86, 329-338. doi: 10.1016/j.earlhumdev.2010.05.010

Laptook, A. R., Shankaran, S., Tyson, J. E., Munoz, B., Bell, E. F., Goldberg, R. N., et al. (2017). Effect of therapeutic hypothermia initiated after 6 hours of age on death or disability among newborns with hypoxic-ischemic encephalopathy: a randomized clinical trial. JAMA 318, 1550-1560. doi: 10.1001/jama.2017. 14972

Leaw, B., Nair, S., Lim, R., Thornton, C., Mallard, C., and Hagberg, H. (2017). Mitochondria, bioenergetics and excitotoxicity: new therapeutic targets in perinatal brain injury. Front. Cell. Neurosci. 11:199. doi: 10.3389/fncel.2017. 00199

Lee, J., Croen, L. A., Lindan, C., Nash, K. B., Yoshida, C. K., Ferriero, D. M., et al. (2005). Predictors of outcome in perinatal arterial stroke: a population-based study. Ann. Neurol. 58, 303-308. doi: 10.1002/ana.20557

Lee, S. T., Chu, K., Sinn, D. I., Jung, K. H., Kim, E. H., Kim, S. J., et al. (2006). Erythropoietin reduces perihematomal inflammation and cell death with eNOS and STAT3 activations in experimental intracerebral hemorrhage. J. Neurochem. 96, 1728-1739. doi: 10.1111/j.1471-4159.2006. 03697.x

Leung, K. S., Galano, J. M., Durand, T., and Lee, J. C. (2015). Current development in non-enzymatic lipid peroxidation products, isoprostanoids and isofuranoids, in novel biological samples. Free Radic Res. 49, 816-826. doi: 10.3109/10715762. 2014.960867

Li, G., Zou, L., Jack, C. R. Jr., Yang, Y., and Yang, E. S. (2007). Neuroprotective effect of Coenzyme Q10 on ischemic hemisphere in aged mice with mutations in the amyloid precursor protein. Neurobiol. Aging 28, 877-882. doi: 10.1016/j. neurobiolaging.2006.05.005

Li, J., Yawno, T., Sutherland, A., Loose, J., Nitsos, I., Bischof, R., et al. (2016). Preterm white matter brain injury is prevented by early administration of umbilical cord blood cells. Exp. Neurol. 283, 179-187. doi: 10.1016/j.expneurol. 2016.06.017

Liu, H., Li, J., Zhao, F., Wang, H., Qu, Y., and Mu, D. (2015a). Nitric oxide synthase in hypoxic or ischemic brain injury. Rev. Neurosci. 26, 105-117. doi: 10.1515/revneuro-2014-0041

Liu, L., Oza, S., Hogan, D., Perin, J., Rudan, I., Lawn, J. E., et al. (2015b). Global, regional, and national causes of child mortality in 2000-13, with projections to inform post-2015 priorities: an updated systematic analysis. Lancet 385 , 430-440. doi: 10.1016/S0140-6736(14)61698-6

Liu, Y., Li, W., Hu, L., Liu, Y., Li, B., Sun, C., et al. (2015c). Downregulation of nitric oxide by electroacupuncture against hypoxicischemic brain damage in rats via nuclear factorkappaB/neuronal nitric oxide synthase. Mol. Med. Rep. 11, 837-842. doi: 10.3892/mmr.2014.2879

Liu, H. T., and Mu, D. Z. (2014). [Inducible nitric oxide synthase and brain hypoxic-ischemic brain damage]. Zhongguo Dang Dai Er Ke Za Zhi 16, $962-$ 967.

Liu, S., Shen, G., Deng, S., Wang, X., Wu, Q., and Guo, A. (2013). Hyperbaric oxygen therapy improves cognitive functioning after brain injury. Neural Regen. Res. 8, 3334-3343. doi: 10.3969/j.issn.1673-5374.2013.35.008

Low, J. A. (2004). Determining the contribution of asphyxia to brain damage in the neonate. J. Obstet. Gynaecol. Res. 30, 276-286. doi: 10.1111/j.1447-0756.2004. 00194.x

Lu, C. J., Guo, Y. Z., Zhang, Y., Yang, L., Chang, Y., Zhang, J. W., et al. (2017). Coenzyme Q10 ameliorates cerebral ischemia reperfusion injury in hyperglycemic rats. Pathol. Res. Pract. 213, 1191-1199. doi: 10.1016/j.prp.2017. 06.005

Lu, Q., Harris, V. A., Rafikov, R., Sun, X., Kumar, S., and Black, S. M. (2015). Nitric oxide induces hypoxia ischemic injury in the neonatal brain via the disruption of neuronal iron metabolism. Redox Biol. 6, 112-121. doi: 10.1016/j.redox.2015. 06.007

Maguire, J. J., Wilson, D. S., and Packer, L. (1989). Mitochondrial electron transport-linked tocopheroxyl radical reduction. J. Biol. Chem. 264, 2146221465.

Mayurasakorn, K., Niatsetskaya, Z. V., Sosunov, S. A., Williams, J. J., Zirpoli, H., Vlasakov, I., et al. (2016). DHA but Not EPA emulsions preserve neurological and mitochondrial function after brain hypoxia-ischemia in neonatal mice. PLoS One 11:e0160870. doi: 10.1371/journal.pone.0160870

McCord, J. M. (1985). Oxygen-derived free radicals in postischemic tissue injury. N Engl. J. Med. 312, 159-163. doi: 10.1056/NEJM198501173120305

Milagros Rocha, M., and Victor, V. M. (2007). Targeting antioxidants to mitochondria and cardiovascular diseases: the effects of mitoquinone. Med. Sci. Monit. 13, RA132-RA145.

Milne, G. L., Yin, H., Hardy, K. D., Davies, S. S., and Roberts, L. J. II (2011). Isoprostane generation and function. Chem. Rev. 111, 5973-5996. doi: 10.1021/ cr200160h

Mirabelli-Badenier, M., Braunersreuther, V., Viviani, G. L., Dallegri, F., Quercioli, A., Veneselli, E., et al. (2011). CC and CXC chemokines are pivotal mediators of cerebral injury in ischaemic stroke. Thromb Haemost 105, 409420. doi: 10.1160/TH10-10-0662

Nakka, V. P., Gusain, A., Mehta, S. L., and Raghubir, R. (2008). Molecular mechanisms of apoptosis in cerebral ischemia: multiple neuroprotective opportunities. Mol. Neurobiol. 37, 7-38. doi: 10.1007/s12035-007-8013-9

Nie, X., Lowe, D. W., Rollins, L. G., Bentzley, J., Fraser, J. L., Martin, R., et al. (2016). Sex-specific effects of N-acetylcysteine in neonatal rats treated with hypothermia after severe hypoxia-ischemia. Neurosci. Res. 108, 24-33. doi: 10.1016/j.neures.2016.01.008

Owen, M. R., Doran, E., and Halestrap, A. P. (2000). Evidence that metformin exerts its anti-diabetic effects through inhibition of complex 1 of the mitochondrial respiratory chain. Biochem. J. 348(Pt 3), 607-614. doi: 10.1042/ bj3480607

Palmer, C. (1995). Hypoxic-ischemic encephalopathy, therapeutic approaches against microvascular injury, and role of neutrophils, PAF, and free radicals. Clin. Perinatol. 22, 481-517. doi: 10.1016/S0095-5108(18)30294-X

Palmer, C., Menzies, S. L., Roberts, R. L., Pavlick, G., and Connor, J. R. (1999). Changes in iron histochemistry after hypoxic-ischemic brain injury in the neonatal rat. J. Neurosci. Res. 56, 60-71. doi: 10.1002/(SICI)10974547(19990401)56:1<60::AID-JNR8<3.0.CO;2-A

Park, D., Shin, K., Choi, E. K., Choi, Y., Jang, J. Y., Kim, J., et al. (2015). Protective effects of N-acetyl-L-cysteine in human oligodendrocyte progenitor cells and restoration of motor function in neonatal rats with hypoxic-ischemic encephalopathy. Evid Based Complement. Alternat. Med. 2015:764251. doi: 10. 1155/2015/764251

Park, M. H., Lee, S. M., Lee, J. W., Son, D. J., Moon, D. C., Yoon, D. Y., et al. (2006). ERK-mediated production of neurotrophic factors by astrocytes promotes neuronal stem cell differentiation by erythropoietin. Biochem. Biophys. Res. Commun. 339, 1021-1028. doi: 10.1016/j.bbrc.2005.10.218

Paton, M. C. B., Mcdonald, C. A., Allison, B. J., Fahey, M. C., Jenkin, G., and Miller, S. L. (2017). Perinatal brain injury as a consequence of preterm birth and intrauterine inflammation: designing targeted stem cell therapies. Front. Neurosci. 11:200. doi: 10.3389/fnins.2017.00200

Peeters-Scholte, C., Braun, K., Koster, J., Kops, N., Blomgren, K., Buonocore, G., et al. (2003). Effects of allopurinol and deferoxamine on reperfusion injury of the brain in newborn piglets after neonatal hypoxia-ischemia. Pediatr. Res. 54, 516-522. doi: 10.1203/01.PDR.0000081297.53793.C6

Perlman, J. M., Wyllie, J., Kattwinkel, J., Atkins, D. L., Chameides, L., Goldsmith, J. P., et al. (2010). Part 11: neonatal resuscitation: 2010 international consensus on cardiopulmonary resuscitation and emergency cardiovascular care science with treatment recommendations. Circulation 122, S516-S538. doi: 10.1161/ CIRCULATIONAHA.110.971127

Perrone, S., Negro, S., Tataranno, M. L., and Buonocore, G. (2010). Oxidative stress and antioxidant strategies in newborns. J. Matern. Fetal Neonatal. Med. 23(Suppl. 3), 63-65. doi: 10.3109/14767058.2010.509940 
Petrosillo, G., Ruggiero, F. M., and Paradies, G. (2003). Role of reactive oxygen species and cardiolipin in the release of cytochrome $c$ from mitochondria. FASEB J. 17, 2202-2208. doi: 10.1096/fj.03-0012com

Petrosillo, G., Ruggiero, F. M., Pistolese, M., and Paradies, G. (2001). Reactive oxygen species generated from the mitochondrial electron transport chain induce cytochrome $\mathrm{c}$ dissociation from beef-heart submitochondrial particles via cardiolipin peroxidation. Possible role in the apoptosis. FEBS Lett. 509, 435-438. doi: 10.1016/S0014-5793(01)03206-9

Reddy, M. K., and Labhasetwar, V. (2009). Nanoparticle-mediated delivery of superoxide dismutase to the brain: an effective strategy to reduce ischemiareperfusion injury. FASEB J. 23, 1384-1395. doi: 10.1096/fj.08-116947

Reddy, P. H. (2006). Mitochondrial oxidative damage in aging and Alzheimer's disease: implications for mitochondrially targeted antioxidant therapeutics. J. Biomed. Biotechnol. 2006, 31372. doi: 10.1155/JBB/2006/31372

Robertson, N. J., Faulkner, S., Fleiss, B., Bainbridge, A., Andorka, C., Price, D., et al. (2013). Melatonin augments hypothermic neuroprotection in a perinatal asphyxia model. Brain 136, 90-105. doi: 10.1093/brain/aws285

Robertson, N. J., Tan, S., Groenendaal, F., Van Bel, F., Juul, S. E., Bennet, L., et al. (2012). Which neuroprotective agents are ready for bench to bedside translation in the newborn infant? J. Pediatr. 160, e544. doi: 10.1016/j.jpeds.2011.12.052

Rutherford, M., Malamateniou, C., Mcguinness, A., Allsop, J., Biarge, M. M., and Counsell, S. (2010a). Magnetic resonance imaging in hypoxic-ischaemic encephalopathy. Early Hum. Dev. 86, 351-360. doi: 10.1016/j.earlhumdev.2010. 05.014

Rutherford, M., Ramenghi, L. A., Edwards, A. D., Brocklehurst, P., Halliday, H., Levene, M., et al. (2010b). Assessment of brain tissue injury after moderate hypothermia in neonates with hypoxic-ischaemic encephalopathy: a nested substudy of a randomised controlled trial. Lancet Neurol. 9, 39-45. doi: 10.1016/ S1474-4422(09)70295-9

Sanderson, T. H., Reynolds, C. A., Kumar, R., Przyklenk, K., and Huttemann, M. (2013). Molecular mechanisms of ischemia-reperfusion injury in brain: pivotal role of the mitochondrial membrane potential in reactive oxygen species generation. Mol. Neurobiol. 47, 9-23. doi: 10.1007/s12035-012-8344-z

Sarkar, S., Barks, J. D., Bhagat, I., and Donn, S. M. (2009). Effects of therapeutic hypothermia on multiorgan dysfunction in asphyxiated newborns: whole-body cooling versus selective head cooling. J. Perinatol. 29, 558-563. doi: 10.1038/jp. 2009.37

Sarkar, S., Donn, S. M., Bapuraj, J. R., Bhagat, I., and Barks, J. D. (2012). Distribution and severity of hypoxic-ischaemic lesions on brain MRI following therapeutic cooling: selective head versus whole body cooling. Arch. Dis. Child Fetal Neonatal Ed 97, F335-F339. doi: 10.1136/fetalneonatal-2011-300964

Saugstad, O. D., Ramji, S., Soll, R. F., and Vento, M. (2008). Resuscitation of newborn infants with $21 \%$ or $100 \%$ oxygen: an updated systematic review and meta-analysis. Neonatology 94, 176-182. doi: 10.1159/000143397

Sekhon, B., Sekhon, C., Khan, M., Patel, S. J., Singh, I., and Singh, A. K. (2003). $\mathrm{N}$-Acetyl cysteine protects against injury in a rat model of focal cerebral ischemia. Brain Res. 971, 1-8. doi: 10.1016/S0006-8993(03)02244-3

Shankaran, S., Laptook, A. R., Ehrenkranz, R. A., Tyson, J. E., Mcdonald, S. A., Donovan, E. F., et al. (2005). Whole-body hypothermia for neonates with hypoxic-ischemic encephalopathy. N. Engl. J. Med. 353, 1574-1584. doi: 10. 1056/NEJM050929

Silachev, D. N., Plotnikov, E. Y., Zorova, L. D., Pevzner, I. B., Sumbatyan, N. V., Korshunova, G. A., et al. (2015). Neuroprotective effects of mitochondria-targeted plastoquinone and thymoquinone in a rat model of brain ischemia/reperfusion injury. Molecules 20, 14487-14503. doi: 10.3390/ molecules200814487

Silveira, R. C., and Procianoy, R. S. (2015). Hypothermia therapy for newborns with hypoxic ischemic encephalopathy. J. Pediatr. (Rio J) 91, S78-S83. doi: 10.1016/j.jped.2015.07.004

Smith, R. A., Hartley, R. C., and Murphy, M. P. (2011). Mitochondria-targeted small molecule therapeutics and probes. Antioxid. Redox Signal. 15, 3021-3038. doi: 10.1089/ars.2011.3969

Tagin, M., Abdel-Hady, H., Ur Rahman, S., Azzopardi, D. V., and Gunn, A. J. (2015). Neuroprotection for perinatal hypoxic ischemic encephalopathy in low- and middle-income countries. J. Pediatr. 167, 25-28. doi: 10.1016/j.jpeds. 2015. 02.056

Ten, V. S., and Starkov, A. (2012). Hypoxic-ischemic injury in the developing brain: the role of reactive oxygen species originating in mitochondria. Neurol. Res. Int. 2012:542976. doi: 10.1155/2012/542976

Tonni, G., Leoncini, S., Signorini, C., Ciccoli, L., and De Felice, C. (2014). Pathology of perinatal brain damage: background and oxidative stress markers. Arch. Gynecol. Obstet. 290, 13-20. doi: 10.1007/s00404-014-3208-6

Torrance, H. L., Benders, M. J., Derks, J. B., Rademaker, C. M., Bos, A. F., Van Den Berg, P., et al. (2009). Maternal allopurinol during fetal hypoxia lowers cord blood levels of the brain injury marker S-100B. Pediatrics 124, 350-357. doi: $10.1542 /$ peds.2008-2228

Turrens, J. F. (2003). Mitochondrial formation of reactive oxygen species. J. Physiol. 552, 335-344. doi: 10.1113/jphysiol.2003.049478

Tuttolomondo, A., Di Raimondo, D., Di Sciacca, R., Pinto, A., and Licata, G. (2008). Inflammatory cytokines in acute ischemic stroke. Curr. Pharm. Des. 14, 3574-3589. doi: 10.2174/138161208786848739

van den Tweel, E. R., Nijboer, C., Kavelaars, A., Heijnen, C. J., Groenendaal, F., and Van Bel, F. (2005). Expression of nitric oxide synthase isoforms and nitrotyrosine formation after hypoxia-ischemia in the neonatal rat brain. J. Neuroimmunol. 167, 64-71. doi: 10.1016/j.jneuroim.2005.06.031

Vannucci, S. J., and Hagberg, H. (2004). Hypoxia-ischemia in the immature brain. J. Exp. Biol. 207, 3149-3154. doi: 10.1242/jeb.01064

Vento, M., Moro, M., Escrig, R., Arruza, L., Villar, G., Izquierdo, I., et al. (2009). Preterm resuscitation with low oxygen causes less oxidative stress, inflammation, and chronic lung disease. Pediatrics 124, e439-e449. doi: 10. 1542/peds.2009-0434

Volpe, J. J. (2001). Perinatal brain injury: from pathogenesis to neuroprotection. Ment. Retard Dev. Disabil. Res. Rev. 7, 56-64. doi: 10.1002/1098-2779(200102)7: $1<56:$ AID-MRDD $1008<3.0$. CO; 2 - A

Wang, J., and Lu, Q. (2008). Expression of T subsets and mIL-2R in peripheral blood of newborns with hypoxic ischemic encephalopathy. World J. Pediatr. 4, 140-144. doi: 10.1007/s12519-008-0028-4

Wasielewski, B., Jensen, A., Roth-Harer, A., Dermietzel, R., and Meier, C. (2012). Neuroglial activation and $\mathrm{Cx} 43$ expression are reduced upon transplantation of human umbilical cord blood cells after perinatal hypoxic-ischemic injury. Brain Res. 1487, 39-53. doi: 10.1016/j.brainres.2012.05.066

Wassink, G., Gunn, E. R., Drury, P. P., Bennet, L., and Gunn, A. J. (2014). The mechanisms and treatment of asphyxial encephalopathy. Front. Neurosci. 8:40. doi: $10.3389 /$ fnins. 2014.00040

Weidinger, A., and Kozlov, A. V. (2015). Biological activities of reactive oxygen and nitrogen species: oxidative stress versus signal transduction. Biomolecules 5, 472-484. doi: 10.3390/biom5020472

Wong, C. H., and Crack, P. J. (2008). Modulation of neuro-inflammation and vascular response by oxidative stress following cerebral ischemia-reperfusion injury. Curr. Med. Chem. 15, 1-14. doi: 10.2174/092986708783330665

Wu, Q., Chen, W., Sinha, B., Tu, Y., Manning, S., Thomas, N., et al. (2015). Neuroprotective agents for neonatal hypoxic-ischemic brain injury. Drug Discov. Today 20, 1372-1381. doi: 10.1016/j.drudis.2015.09.001

Zhao, M., Zhu, P., Fujino, M., Zhuang, J., Guo, H., Sheikh, I., et al. (2016). Oxidative stress in hypoxic-ischemic encephalopathy: molecular mechanisms and therapeutic strategies. Int. J. Mol. Sci. 17:E2078. doi: 10.3390/ijms17122078

Conflict of Interest Statement: The authors declare that the research was conducted in the absence of any commercial or financial relationships that could be construed as a potential conflict of interest.

Copyright (c) 2019 Qin, Cheng, Zhong, Mahgoub, Akter, Fan, Aldughaim, Xie, Qin, Gu, Jian, Xiong and Liu. This is an open-access article distributed under the terms of the Creative Commons Attribution License (CC BY). The use, distribution or reproduction in other forums is permitted, provided the original author(s) and the copyright owner(s) are credited and that the original publication in this journal is cited, in accordance with accepted academic practice. No use, distribution or reproduction is permitted which does not comply with these terms. 